\section{BRAZIULIAN JOURNAL \\ OF MEDICAL AND BIOLOGICAL RLSF.ARCH}

www.bjournal.com.br
ISSN 0100-879X

Volume 42 (11) 993-1118 November 2009

BIOMEDICAL SCIENCES

AND

CLINICAL INVESTIGATION

Braz J Med Biol Res, November 2009, Volume 42(11)1039-1043

Peritoneal and serum interleukin-18 levels are not increased in women with minimum or mild endometriosis

C. Glitz, C.A. Souza, G.P. Rodini, V. Genro, J.P. Bilibio, M. Senger and J.S. Cunha-Filho

The Brazilian Journal of Medical and Biological Research is partially financed by
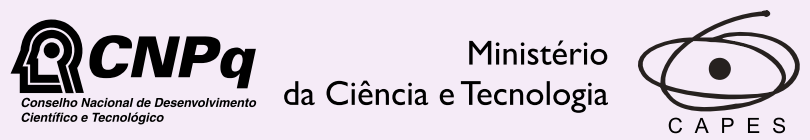

Ministério da Educação

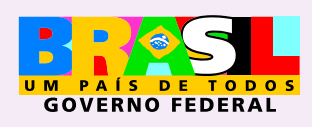

DFAPESP

Institutional Sponsors 


\title{
Peritoneal and serum interleukin-18 levels are not increased in women with minimum or mild endometriosis
}

\author{
C. Glitz, C.A. Souza, G.P. Rodini, V. Genro, J.P. Bilibio, \\ M. Senger and J.S. Cunha-Filho \\ Departamento de Obstetrícia e Ginecologia, Hospital de Clínicas de Porto Alegre, \\ Faculdade de Medicina, Universidade Federal do Rio Grande do Sul, Porto Alegre, RS, Brasil
}

\begin{abstract}
Interleukin-18 (IL-18) is a cytokine that belongs to the IL-1 family. Endometriosis is strongly associated with sub-fertility, and affects about $15 \%$ of women of reproductive age. IL-18 may favor the progression of endometriosis. The objective of the present study was to determine the concentration of IL-18 in the serum and peritoneal fluid of infertile women with endometriosis. Forty infertile and 25 fertile women were screened in a teaching hospital. Thirty-four infertile patients with minimal or mild endometriosis and 22 fertile controls were enrolled in the study. The primary outcome was the estimate of IL-18 levels and the secondary outcome was the correlation between serum and peritoneal levels of IL-18. There were no differences between the two groups regarding age, body mass index and levels of peritoneal fluid IL-18 (mean \pm SD): $290.85 \pm 173.02 \mathrm{pg} / \mathrm{mL}$ for infertile women vs $374.21 \pm 330.15 \mathrm{pg} / \mathrm{mL}$ for controls; or serum IL-18: $391.07 \pm 119.71 \mathrm{pg} / \mathrm{mL}$ for infertile women vs 373.42 $\pm 129.11 \mathrm{pg} / \mathrm{mL}$ for controls. However, a positive association was found between serum and peritoneal IL-18 levels in patients with endometriosis: $r=0.794, P=0.0001$. All measurements were carried out at the same time by the Human IL-18 Immuno Assay ELISA kit (MBL Co. Ltd., Japan). The present study did not find evidence supporting the hypothesis that IL-18 levels are associated with infertility in women with minimal and mild endometriosis, although a positive correlation was detected in these women between peritoneal and serum levels of IL-18.
\end{abstract}

Key words: Cytokines; Endometriosis; IL-18; Peritoneal fluid; Infertility

\section{Introduction}

The association between endometriosis and infertility is well known. It has been estimated that about $20-25 \%$ of infertile women have endometriosis $(1,2)$. Patients with moderate or severe endometriosis have infertility secondary to anatomic causes. However, for infertile women with minimal or mild endometriosis, the cause of infertility is not fully understood but is thought to involve hormonal $(3,4)$, immunological (5), proliferative (endometrial), and uterine alterations $(2,6)$.

Interleukin-18 (IL-18) is a cytokine that belongs to the IL-1 family, originally identified as interferon gamma (IFN-y) in Kupffer cells and macrophages (7). IL-18 activates natural killer (NK) cells and also plays a relevant role in the protection against bacterial infections. It plays a central role in the inflammatory cascade and in the process of innate and acquired immunity as a result of its ability to induce the production of IFN-y in T lymphocytes and NK cells $(7,8)$.
Moreover, IL-18 acts in synergy with IL-12 to promote the development of the $\mathrm{T}$ helper response and a shift to the Th1 pattern $(5,8)$.

Several immunological abnormalities have been described in infertile patients with minimal and mild endometriosis: abnormal NK cell function $(9,10)$, reduced cytotoxic effect of lymphocytes and macrophage (9), imbalanced Th1/Th2 response $(5,11)$, and many studies have found high levels of cytokines in the peritoneal fluid of women with endometriosis (1). These alterations may play a role in the development and progression of endometriosis and infertility $(12,13)$.

In addition, some cytokines have been identified in the peritoneal fluid. The cytokines found in women with endometriosis include: interleukins (IL-1, IL-4, IL-5, IL-6, IL-8, IL-10, IL-12, IL-13), IFN-y, tumor necrosis factor (TNF), and others (12). The abnormal expression of several cytokines

Correspondence: J.S. Cunha-Filho, Rua Ramiro Barcellos, 2350, Sala 1124, 90035-003 Porto Alegre, RS, Brasil. E-mail: sabino@ via-rs.net/grodini@terra.com.br

Received April 16, 2009. Accepted September 23, 2009. Available online October 26, 2009. 
by the activation of macrophage, such as IL-1, IL-6, IL-8, and TNF, in the peritoneal fluid of women with endometriosis can contribute to an unfavorable peritoneal environment, favoring the growth of endometrial cells and the establishment of endometriosis $(13,14)$.

Literature data concerning the role of IL-18 in endometriosis are contradictory, probably because the patient groups studied were not homogeneous and most of the studies did not focus on infertile patients with minimal/mild endometriosis.

Some investigators have already studied the association between IL-18 and endometriosis. Arici et al. (8) found measurable levels of IL-18 in the peritoneal fluid of patients with treated endometriosis to be significantly higher than those of the control group with endometriosis without treatment (means \pm SEM, $91.1 \pm 6.5$ vs $59.4 \pm 2 \mathrm{pg} / \mathrm{mL}$ ) (8). A similar result was obtained by Oku et al. (592 \pm 108 vs $260 \pm 55 \mathrm{pg} / \mathrm{mL}$ ) who also performed immunohistochemical analysis (15-17). Moreover, Zhang et al. (18) determined the concentration of IL-18 in the peritoneal fluid and serum of women with endometriosis. They reported that peritoneal concentration of IL-18 was significantly lower in patients with endometriosis $(144.8 \mathrm{pg} / \mathrm{mL})$ than in women without endometriosis $(653.4 \mathrm{pg} / \mathrm{mL})$. Luo et al. (19) reported down-regulation of IL-18 mRNA expression in ectopic and eutopic endometrium of women with endometriosis. More recently, Fairbanks et al. (20) showed that patients with severe endometriosis have higher levels of IL-12 in the peritoneal fluid irrespective of IL-18 levels (means \pm SEM, $142 \pm 23$ vs $112 \pm 29 \mathrm{pg} / \mathrm{mL}$ ).

Since endometriosis is associated with sub-fertility and IL-18 may favor the progression of endometriosis, we expected that IL-18 would be associated with infertility. We determined the levels of IL-18 in the serum and peritoneal fluid of infertile women with minimal/mild endometriosis. As the peritoneal fluid may reflect a systemic inflammatory scenario, we also attempted to correlate the peritoneal and serum IL-18 levels.

\section{Patients and Methods}

A cross-sectional study was conducted on 56 patients enrolled from March 2006 to December 2007 at Hospital de Clínicas de Porto Alegre when seeking care for the investigation of infertility or tubal ligation.

Thirty-four patients with minimal or mild endometriosis were submitted to laparoscopy to investigate infertility. Infertility was defined as the inability of a couple to achieve pregnancy after one year of regular unprotected sexual intercourse (16). Endometriosis was diagnosed during laparoscopy and categorized according to the classification proposed by the American Society for Reproductive Medicine (ASRM, 1997) (16). All patients had peritoneal implants. The same investigator performed all endoscopic procedures. Other causes of infertility were excluded by hysterosalpingography, sperm evaluation, and measurements of serum follicle-stimulating hormone, prolactin and thyroid-stimulating hormone levels on the third day of the menstrual cycle. All patients were in the first menstrual phase and none of them had been taking hormonal medications for at least 3 months prior to surgery.

The control group consisted of 22 patients who underwent laparoscopy for tubal ligation. None of these patients were diagnosed with endometriosis, all of them were fertile and none had a significant past medical history. Once again, all patients were in the first menstrual phase and none of them had been on hormonal medications for at least 3 months prior to surgery.

The samples of peritoneal fluid ( 3 to $6 \mathrm{~mL}$ ) were collected during the laparoscopic procedure under general anesthesia, immediately after the introduction of the second trocar, and the fluid was aspirated from the anterior or posterior peritoneal deflection. Samples were not collected when the presence of bleeding in the cavity was detected and the peritoneal cavity was not washed. The blood samples were collected at the time of the laparoscopic procedure in all patients. All samples were centrifuged and stored at $-80^{\circ} \mathrm{C}$ until the time for determination.

Clinical data regarding menstrual cycle, obstetrical history, previous surgical procedures, and history of hormone use were also obtained by means of an appropriate questionnaire. All patients and control subjects who participated in this study signed an informed consent form. The study was approved by the Ethics Committee of Hospital de Clínicas de Porto Alegre.

The serum and peritoneal IL-18 levels were determined with the Human IL-18 Immuno Assay ELISA kit (MBL Co. Ltd., Japan). This assay has the ability to specifically detect IL-18 in human secretions with a high sensitivity of 12.5 $\mathrm{pg} / \mathrm{mL}$. The minimal estimated detection would be $12.5 \pm$ $6.25 \mathrm{pg} / \mathrm{mL}$. The laparoscopy procedure was performed independently of the day of the menstrual cycle. There was a nonsignificant correlation between serum and peritoneal IL-18 levels and the day of the menstrual day (data not shown).

For statistical analysis, data with nonparametric distribution are reported as median values with the $95 \%$ confidence interval and those with parametric distribution as means \pm SD. The Student $t$-test was used to compare means, the Mann-Whitney test to compare median values and the Spearman test for correlation analysis. When $\mathrm{P}<0.05$, the samples were considered to be statistically different.

The sample size was calculated based on previously published studies, with values of $\mathrm{P} \beta$ of $80 \%$ and $\mathrm{Pa}$ of $5 \%$ (17). The calculated number of patients was 50 .

\section{Results}

The clinical and demographic characteristics of the two groups did not differ. Mean \pm SD age was $31.51 \pm 4.54$ years 
for the group with endometriosis and similar $34.23 \pm 3.56$ years for the control group $(P>0.05)$. Mean body mass index was also similar for the two groups, i.e, $24.21 \pm 4.33$ $\mathrm{kg} / \mathrm{m}^{2}$ for the group with endometriosis and $24.69 \pm 1.91$ $\mathrm{kg} / \mathrm{m}^{2}$ for the control group ( $\mathrm{P}>0.05$ ). Of 34 patients with endometriosis, 21 showed mild and 13 minimal disease.

The means \pm SD of the peritoneal and serum levels of IL-18 in patients with endometriosis were $290.85 \pm 173.02$ and $391.07 \pm 119.71 \mathrm{pg} / \mathrm{mL}$, respectively (Student $t$-test, $P>0.05)$. In the control group, the peritoneal and serum levels of IL-18 were $374.21 \pm 330.15$ and $373.42 \pm 129.11$ $\mathrm{pg} / \mathrm{mL}$, respectively (Student $t$-test, $\mathrm{P}>0.05$ ).

The means \pm SD of IL-18 levels in peritoneal fluid according to the endometriosis stage were analyzed. In stage I, the levels were $37.7 \pm 35.4 \mathrm{pg} / \mathrm{mL}$ and in stage II, 48.2 $\pm 59.3 \mathrm{pg} / \mathrm{mL}$. There was no statistically significant difference between minimal and mild endometriosis (Student $t$-test, $\mathrm{P}>0.05)$.

The correlation between serum and peritoneal fluid IL-18 levels was estimated and a strong and positive association was found both in the control group $(r=0.794, P=0.001)$ and in patients with endometriosis $(r=0.722, P=0.004)$, as shown in Figure 1. Thus, this correlation between the peritoneal fluid and the serum IL-18 levels reflects a systemic inflammatory response in both groups.

In addition, the stage of endometriosis was not associated with IL-18 levels (serum or peritoneal; data not shown).

\section{Discussion}

This study did not find a significant difference in the IL-18 levels of serum and the peritoneal cavity of infertile women with minimal and mild endometriosis compared to the control group. These findings suggest that IL-18 does not participate in the infertility of patients with $\mathrm{mild} / \mathrm{minimal}$ endometriosis. However, a strong and positive correlation between serum and peritoneal IL-18 levels was found, possibly indicating a systemic immunoregulatory role of IL-18 and not of a solely local (peritoneal) production of IL-18.

As previously reported, several cytokines were associated with the pathogenesis of endometriosis $(12,14)$. Alteration in the immunological system related to retrograde menstruation allows the establishment of peritoneal implants that may result in endometriosis. Some studies have suggested that endometriosis may be a type of autoimmune disease $(8,21)$. In addition, circulating monocytes showed an increased activation in women with endometriosis. Under basal and stimulated conditions, these cells show higher levels of TNF- $\alpha$, IL- 6 and IL-8 production when compared to cells of unaffected patients (21).

$\mathrm{IL}-18$ has an immunoregulatory function and is predominantly produced by activated macrophages. Furthermore, it shares functional properties with IL-12 and structural similarities with the IL-1 family, with effects that are indepen-

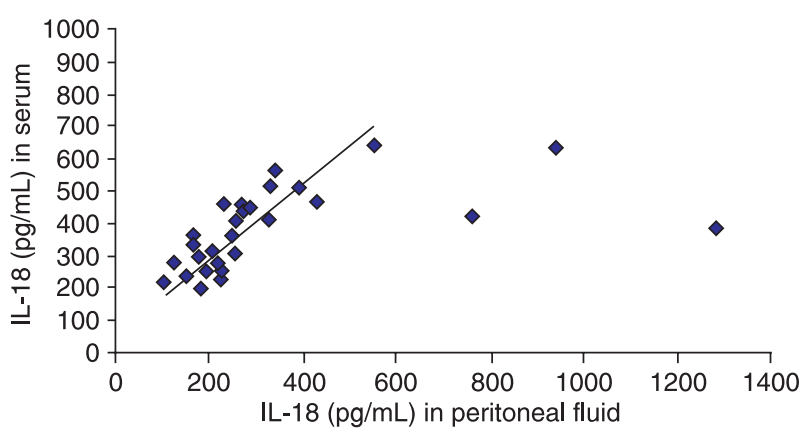

Figure 1. Correlation of serum IL-18 levels and peritoneal IL-18 levels for controls $(\mathrm{N}=22)$ and infertile endometriotic patients ( $\mathrm{N}$ = 34). $P=0.001, r=0.794$ for controls; $P=0.004, r=0.722$ for infertile patients with endometriosis (Spearman correlation test).

dent of both. IL-18 induces a Th1 immunological response by inducing the production of IFN- $\mathrm{Y}$ by macrophages, $\mathrm{T}$ lymphocytes and NK cells (22-24).

To date, four studies have evaluated IL-18 levels in patients with endometriosis, with discrepant results $(8,17,20,24)$. Zhang et al. (24) did not find a correlation between peritoneal and serum concentrations of IL-18. Other studies did not evaluate this correlation, and this was the reason why we were interested in the determination of both serum and peritoneal IL-18 levels and in the estimate of their correlation.

Arici et al. (8) and Oku et al. (17) found high levels of IL-18 in the peritoneal fluid of women with endometriosis when compared to a control group. In contrast, Zhang et al. (24) found reduced levels of IL-18 in the peritoneal fluid of patients with endometriosis when compared to the group of patients submitted to tubal ligation. We questioned whether the use of different kits for the determination of IL-18 (Bender Medsystems, Santa Cruz Biotechnology, USA, versus MBL) would be one of the reasons for the conflicting results obtained in these studies, since the numerical values presented were very distinct although all of them used ELISA.

Our results agree with those of Fairbanks et al. (20) who found no difference in IL-18 levels either in serum or in peritoneal samples from patients with endometriosis (20), but found a significant increase in IL-12 levels in patients with endometriosis and with more advanced stages of the disease. This suggests an alternative pathway in the induction of a Th1 inflammatory response in patients with endometriosis.

When we compare our study with these studies, we can see that the profile of the study group in which the IL-18 was determined was also different. The selection of subjects can interfere with the final result, particularly when one works with new and variable methods and techniques.

The study of Arici et al. (8) compared a group of patients with endometriosis who were previously treated 
with a $\mathrm{GnRH}$ agonist to the group of subjects who had not received any treatment. It is not known if the use of an agonist could interfere with the peritoneal fluid, altering the result of IL-18 measurement. All previous studies included patients with endometriosis who presented either pelvic pain and/or infertility.

Our investigation showed statistical power and appropriate care in the composition of the study and the control group (stages I and II of endometriosis and fertile women without endometriosis, respectively) in order to test the hypothesis of an association between IL-18 in the serum and peritoneal fluid of women with infertility and endometriosis. The results do not rule out the influence of IL-18 in women with endometriosis and pelvic pain since the main focus was the subgroup of infertile patients with mild/minimal endometriosis.

In addition, it has been recently demonstrated that patients who are homozygotes for IL-2 with allele $\mathrm{C}$ have a

\section{References}

1. Candiani GB, Vercellini P, Fedele L, Colombo A, Candiani M. Mild endometriosis and infertility: a critical review of epidemiologic data, diagnostic pitfalls, and classification limits. Obstet Gynecol Surv 1991; 46: 374-382.

2. Giudice LC, Kao LC. Endometriosis. Lancet 2004; 364: 1789-1799.

3. Cunha-Filho JS, Gross JL, Lemos NA, Brandelli A, Castillos $M$, Passos EP. Hyperprolactinemia and luteal insufficiency in infertile patients with mild and minimal endometriosis. Horm Metab Res 2001; 33: 216-220.

4. Cunha-Filho JS, Gross JL, Bastos de Souza CA, Lemos NA, Giugliani C, Freitas F, et al. Physiopathological aspects of corpus luteum defect in infertile patients with mild/minimal endometriosis. J Assist Reprod Genet 2003; 20: 117-121.

5. Podgaec S, Abrao MS, Dias JA Jr, Rizzo LV, de Oliveira RM, Baracat EC. Endometriosis: an inflammatory disease with a Th2 immune response component. Hum Reprod 2007; 22: 1373-1379.

6. Schor E, da Silva I, Sato H, Baracat EC, Girao MJ, de Freitas V. P27Kip1 is down-regulated in the endometrium of women with endometriosis. Fertil Steril 2009; 91: 682-686.

7. Dinarello CA. Interleukin-18. Methods 1999; 19: 121-132.

8. Arici A, Matalliotakis I, Goumenou A, Koumantakis G, Vassiliadis S, Mahutte NG. Altered expression of interleukin-18 in the peritoneal fluid of women with endometriosis. Fertil Steril 2003; 80: 889-894.

9. Hernandez Guerrero CA, Vadillo Ortega F, Tlapanco Barba R, Arriaga Pizano L, Cerbulo Vazquez A, Gonzalez Jimenez $\mathrm{MA}$, et al. [Changes in the systemic immunologic response in association with endometriosis using an animal model]. Ginecol Obstet Mex 2002; 70: 171-181.

10. Somigliana E, Vigano P, Gaffuri B, Candiani M, Busacca M, Di Blasio AM, et al. Modulation of NK cell lytic function by endometrial secretory factors: potential role in endometriosis. Am J Reprod Immunol 1996; 36: 295-300.

11. Antsiferova YS, Sotnikova NY, Posiseeva LV, Shor AL. Changes in the T-helper cytokine profile and in lymphocyte greater susceptibility to the development of endometriosis. Conversely, the polymorphisms of the IL-18 and -12 genes were not related to endometriosis. Although Hsieh et al. (25) did not study only infertile women, our results agree with theirs, removing IL-18 from the pathogenic pathway of endometriosis (25).

In summary, women with minimal or mild endometriosis did not show any alteration in the concentration of IL-18 in serum or peritoneal fluid. We found no difference in IL-18 in patients or controls with or without infertility due to minimal or mild endometriosis.

\section{Acknowledgments}

Research supported by CNPq, Fundo de Incentivo à Pesquisa (FIPE) do Hospital de Clínicas de Porto Alegre, CAPES and FAPERGS.

activation at the systemic and local levels in women with endometriosis. Fertil Steril 2005; 84: 1705-1711.

12. Harada T, Iwabe T, Terakawa N. Role of cytokines in endometriosis. Fertil Steril 2001; 76: 1-10.

13. Kyama CM, Debrock S, Mwenda JM, D'Hooghe TM. Potential involvement of the immune system in the development of endometriosis. Reprod Biol Endocrinol 2003; 1: 123.

14. Bedaiwy MA, Falcone T, Sharma RK, Goldberg JM, Attaran $\mathrm{M}$, Nelson DR, et al. Prediction of endometriosis with serum and peritoneal fluid markers: a prospective controlled trial. Hum Reprod 2002; 17: 426-431.

15. McMurray RW, Suwannaroj S, Ndebele K, Jenkins JK. Differential effects of sex steroids on $T$ and $B$ cells: modulation of cell cycle phase distribution, apoptosis and bcl-2 protein levels. Pathobiology 2001; 69: 44-58.

16. Revised American Society for Reproductive Medicine Classification of Endometriosis: 1996. Fertil Steril 1997; 67: 817-821.

17. Oku H, Tsuji Y, Kashiwamura SI, Adachi S, Kubota A, Okamura $\mathrm{H}$, et al. Role of IL-18 in pathogenesis of endometriosis. Hum Reprod 2004; 19: 709-714.

18. Zhang Y, Peng LX, Meng L. [Measurements of interleukin-18 in peritoneal fluid and serum of patients with endometriosis]. Zhong Nan Da Xue Xue Bao Yi Xue Ban 2005; 30: 731732.

19. Luo Q, Ning W, Wu Y, Zhu X, Jin F, Sheng J, et al. Altered expression of interleukin-18 in the ectopic and eutopic endometrium of women with endometriosis. J Reprod Immunol 2006; 72: 108-117.

20. Fairbanks F, Abrao MS, Podgaec S, Dias JA Jr, de Oliveira RM, Rizzo LV. Interleukin-12 but not interleukin-18 is associated with severe endometriosis. Fertil Steril 2009; 91: 320-324.

21. Dmowski WP. Immunological aspects of endometriosis. Int J Gynaecol Obstet 1995; 50 (Suppl 1): S3-S10.

22. Blankenberg S, Tiret L, Bickel C, Peetz D, Cambien F, Meyer $\mathrm{J}$, et al. Interleukin-18 is a strong predictor of cardiovascular 
death in stable and unstable angina. Circulation 2002; 106 : 24-30.

23. Stuyt RJ, Netea MG, Geijtenbeek TB, Kullberg BJ, Dinarello $C A$, van der Meer JW. Selective regulation of intercellular adhesion molecule-1 expression by interleukin-18 and interleukin-12 on human monocytes. Immunology 2003; 110: 329-334.

24. Zhang X, Lin J, Qian Y, Deng L. Decreased levels of inter- leukin-18 in peritoneal fluid but not in serum of patients with endometriosis. Fertil Steril 2004; 81: 1229-1234.

25. Hsieh YY, Chang CC, Tsai FJ, Hsu CM, Lin CC, Tsai CH. Interleukin-2 receptor beta (IL-2R beta)- $627^{*} \mathrm{C}$ homozygote but not IL-12R beta 1 codon 378 or IL-18 105 polymorphism is associated with higher susceptibility to endometriosis. Fertil Steril 2005; 84: 510-512. 